\title{
Coronary fractional flow reserve in bifurcation stenoses: what have we learned?
}

Joo Myung Lee', MD, MPH; Bon-Kwon Koo ${ }^{1,2 *}, \mathrm{MD}$, PhD; Indulis Kumsars³ ${ }^{3}$ MD; Nick Curzen ${ }^{4}, \mathrm{BM}, \mathrm{PhD}$; Vikas Thondapu ${ }^{5}$, MD; Peter Barlis ${ }^{5,6}, \mathrm{MD}, \mathrm{PhD}$; Javier Escaned ${ }^{7,8}, \mathrm{MD}, \mathrm{PhD}$

1. Department of Internal Medicine and Cardiovascular Center, Seoul National University Hospital, Seoul, South Korea;

2. Institute on Aging, Seoul National University, Seoul, South Korea; 3. Latvian Center of Cardiology, Paul Stradins Clinical Hospital, Riga, Latvia; 4. University Hospital of Southampton \& Faculty of Medicine, University of Southampton, Southampton, United Kingdom; 5. Department of Medicine, University of Melbourne, Melbourne, Australia; 6. Department of Cardiology, The Northern Hospital, Victoria, Australia; 7. Hospital Clinico San Carlos and Centro Nacional de Investigaciones Cardiovasculares Carlos III (CNIC), Madrid, Spain; 8. Faculty of Medicine, Complutense University of Madrid, Madrid, Spain

The references can be found in the online version of this paper at the following website: http://www.pcronline.com/eurointervention/V_issue/13

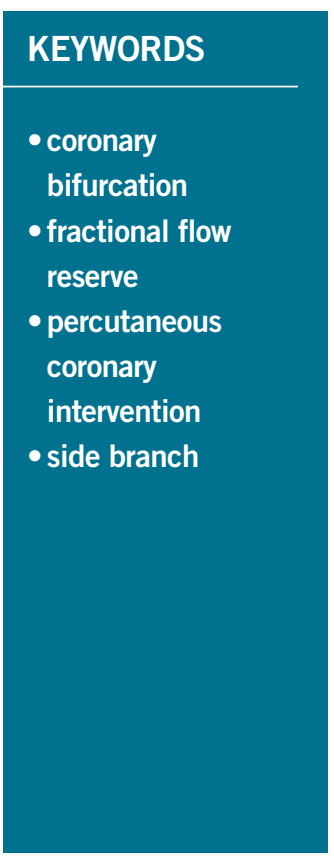

\section{Abstract}

Fractional flow reserve (FFR) is a useful tool for the evaluation of coronary bifurcation lesions. FFR can guide treatment strategy, simplify the procedure and reduce unnecessary complex interventions. However, the application of FFR to complex bifurcation lesions requires a comprehensive understanding of its roles and potential pitfalls. Furthermore, FFR should be interpreted in the context of complex bifurcation anatomy and physiology rather than as a simple number. Finally, it should be recalled that the ischaemic burden is more important than the presence of ischaemia, and the risk/benefit of a complex intervention should be incorporated into the treatment decision after FFR measurement.

\footnotetext{
*Corresponding author: Department of Internal Medicine and Cardiovascular Center, Seoul National University Hospital, 101 Daehang-ro, Chongno-gu, Seoul, 110-744, Republic of Korea.E-mail: bkkoo@snu.ac.kr
} 


\section{Abbreviations}

FFR

fractional flow reserve

LAD

left anterior descending artery

LCX left circumflex artery

PCI percutaneous coronary intervention

QCA

\section{Introduction}

Coronary bifurcation lesions possess unique anatomic and physiologic characteristics. The amount of myocardium supplied by the side branch is variable, the pattern of luminal narrowing is complex and differs between main and side branches, and the coronary flow through the main vessel and side branch changes dynamically during the intervention ${ }^{1}$. Fractional flow reserve (FFR) estimates the ratio of maximal flow in the presence of coronary artery stenosis to the normal maximal flow ${ }^{2}$. Clinically, FFR is measured by the ratio of distal coronary pressure to aortic pressure under the condition of pharmacologically induced hyperaemia. An FFR-guided intervention strategy has been shown to improve clinical outcomes over medical treatment or an angiography-guided intervention strategy in patients with coronary artery disease ${ }^{3-5}$. While FFR-guided bifurcation intervention has been demonstrated to be safe and effective, the application of FFR to bifurcation lesions requires a comprehensive understanding of its roles and potential pitfalls. In this review, we focus on the roles and potential drawbacks of FFR in bifurcation lesions.

\section{FFR for the guidance of revascularisation in coronary bifurcation lesions}

The inherent limitations of angiographic evaluation for bifurcation lesions are well known ${ }^{6-9}$. Although invasive imaging tools such as intravascular ultrasound or optical coherence tomography can

provide complementary anatomical information, their diagnostic accuracy in predicting the functional significance of bifurcation lesions has been reported to be relatively low (Figure 1) ) $^{1,10,11}$.

A large part of the clinical benefit of FFR-guided revascularisation is the reduction of percutaneous coronary intervention (PCI)-associated complications in vessels that do not require revascularisation. This benefit is likely to be maximal in patients with bifurcation lesions, as PCI for bifurcation lesions is a predictor of periprocedural myocardial infarction ${ }^{12}$, and stent thrombosis is more frequent after stenting for bifurcation lesions ${ }^{13}$.

Before the intervention, the use of FFR is generally recommended to evaluate the functional significance of main branch stenosis or pure side branch stenosis (Medina 0,0,1) (Table 1). During PCI, FFR is a useful tool to decide whether additional interventions are required in the jailed side branches. Following the work by Koo et al, several studies have consistently shown the limitations of angiographic \% diameter stenosis (\%DS) in identifying functionally significant jailed side branches (Table 2, Figure 2A) (14-17 $^{\text {. These results }}$ imply that FFR can simplify bifurcation PCI by restricting additional treatment of jailed side branches to those without functional significance. However, the operator needs to balance the risk and benefit of FFR measurement for jailed side branches. FFR measurement is most effective when measured in a large side branch with a short ostial lesion.

FFR is also useful to assess the procedural success and to predict functional and clinical outcomes after side branch intervention (Table 1). Through serial FFR measurements, Koo et al showed that side branch FFR was not changed significantly during followup $(0.86 \pm 0.06$ to $0.84 \pm 0.01, \mathrm{p}=0.4$ in a kissing balloon group and $0.87 \pm 0.06$ to $0.89 \pm 0.07, \mathrm{p}=0.1$ in a non-kissing balloon group, respectively) (Table 2) ${ }^{9}$. The Nordic-Baltic Bifurcation III trial

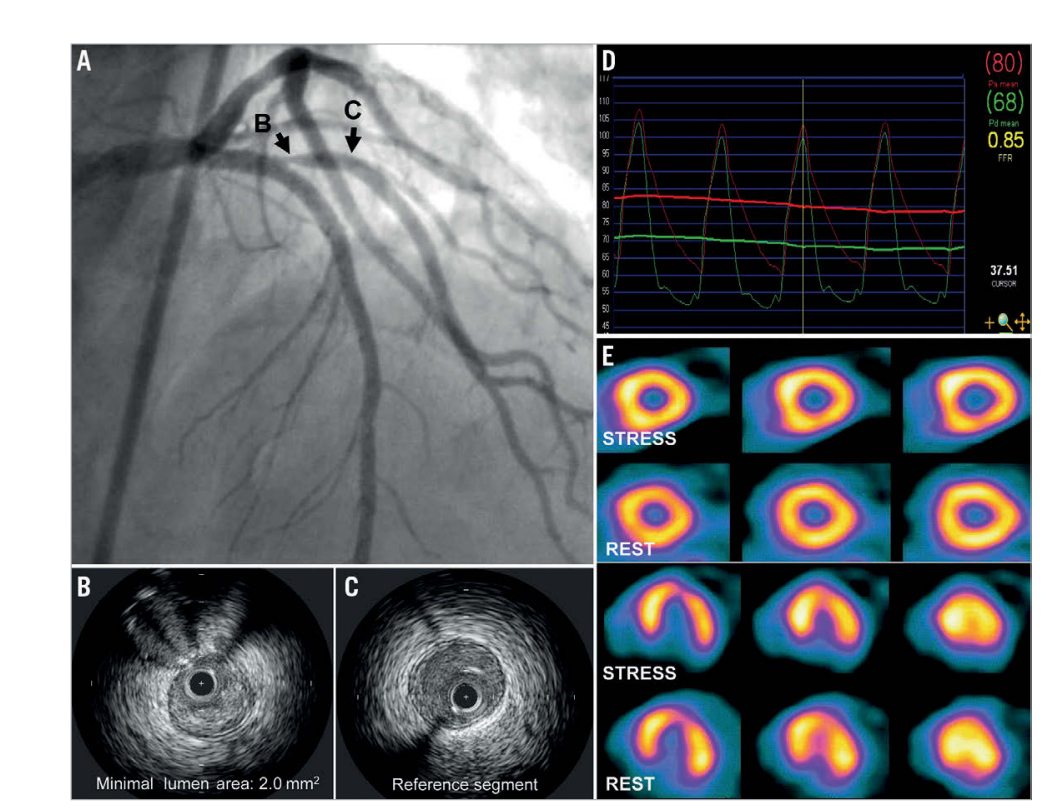

Figure 1. The discrepancy between the anatomical and the functional significance of a side branch. Angiography showed a significant stenosis at the ostium of a large first diagonal branch (A). By intravascular ultrasound, minimal lumen area at the ostium was $2.0 \mathrm{~mm}^{2}(B \& C)$. Nonetheless, FFR of a diagonal branch was 0.85 (D) and there was no reversible perfusion decrease in a myocardial perfusion imaging study (E). 
Table 1. FFR during bifurcation intervention.

\begin{tabular}{|l|l|l|}
\hline Pre-intervention & \begin{tabular}{l}
$|c|$ \\
\multicolumn{1}{|c|}{ FFR is useful } \\
To assess the functional significance of MB \\
To assess the functional significance of pure SB stenosis
\end{tabular} & $\begin{array}{l}\text { Small SB } \\
\text { To determine functional significance of SB when there is } \\
\text { a significant MB stenosis } \\
\text { SB FFR to predict the functional significance of jailed SB }\end{array}$ \\
\hline Post MB stenting & $\begin{array}{l}\text { To assess the functional significance of jailed SB and to } \\
\text { predict the outcomes }\end{array}$ & $\begin{array}{l}\text { Small SB } \\
\text { Long diffuse, highly angulated or calcified SB } \\
\text { SB slow flow }\end{array}$ \\
\hline Post SB angioplasty & $\begin{array}{l}\text { To assess SB procedural success and to predict the } \\
\text { outcomes after KBI }\end{array}$ & $\begin{array}{l}\text { SB slow flow } \\
\text { SB severe dissection }\end{array}$ \\
\hline Post SB stenting & To evaluate residual ischaemia & To predict procedural outcomes of complex two stenting \\
\hline FFR: fractional flow reserve; KBl: kissing balloon inflation; MB: main branch; SB: side branch
\end{tabular}

substudy showed similar findings ${ }^{16}$. Therefore, immediate postintervention side branch FFR appears to be a useful index to predict the functional outcomes of the jailed side branches during followup (Table 1, Figure 2B). However, functional and angiographic late loss is also dependent on the degree of injury from the intervention. After two-stenting, FFR can be helpful to detect the residual ischaemia. However, it should be noted that a high side branch FFR does not always guarantee procedural success and favourable clinical outcomes ${ }^{1,18}$.

\section{Clinical outcomes of FFR-guided side branch intervention strategy}

A previous study comparing clinical outcomes between patients undergoing side branch intervention with and without FFR-guided revascularisation ${ }^{9}$ showed that there was no difference in ninemonth clinical outcomes between the two groups. However, the FFR-guided group received fewer side branch interventions $(30 \%$ in the FFR-guided vs. $45 \%$ in the angiography-guided group, $\mathrm{p}=0.03$ ). The recent DKCRUSH-VI study randomly assigned patients with Medina 1,1,1/0,1,1 bifurcation lesions into an FFRguided side branch treatment group $(n=160)$ versus an angiography-guided side branch treatment group $(n=160)$ (Table 2) ${ }^{19}$. The angiography-guided group received more side branch intervention (angioplasty: $56.3 \%$ vs. $63.1 \%, \mathrm{p}=0.07$; stenting: $25.9 \%$ vs. $38.1 \%, \mathrm{p}=0.01$ ) without any difference in major adverse cardiac events at one year $(18.1 \%$ vs. $18.1 \%, p=1.00)$. Interestingly, the restenosis rate at the distal main vessel was higher in the angiography-guided group $(9.2 \%$ vs. $1.2 \%, p=0.01)$ (Table 2$)$. These study results demonstrated the benefit (less unnecessary side branch intervention) and limitation (no benefit in clinical outcomes) of FFR-guided side branch intervention when used in general bifurcation lesions.

\section{Theoretical and practical limitations of FFR in bifurcation lesions \\ LOW FFR VS. CLINICAL RELEVANCE}

It is well established that myocardial ischaemic burden is clinically more important than the simple presence of ischaemia ${ }^{20,21}$. As side branch territory is smaller than main branch territory, not all side branches with low FFR will cause clinically relevant
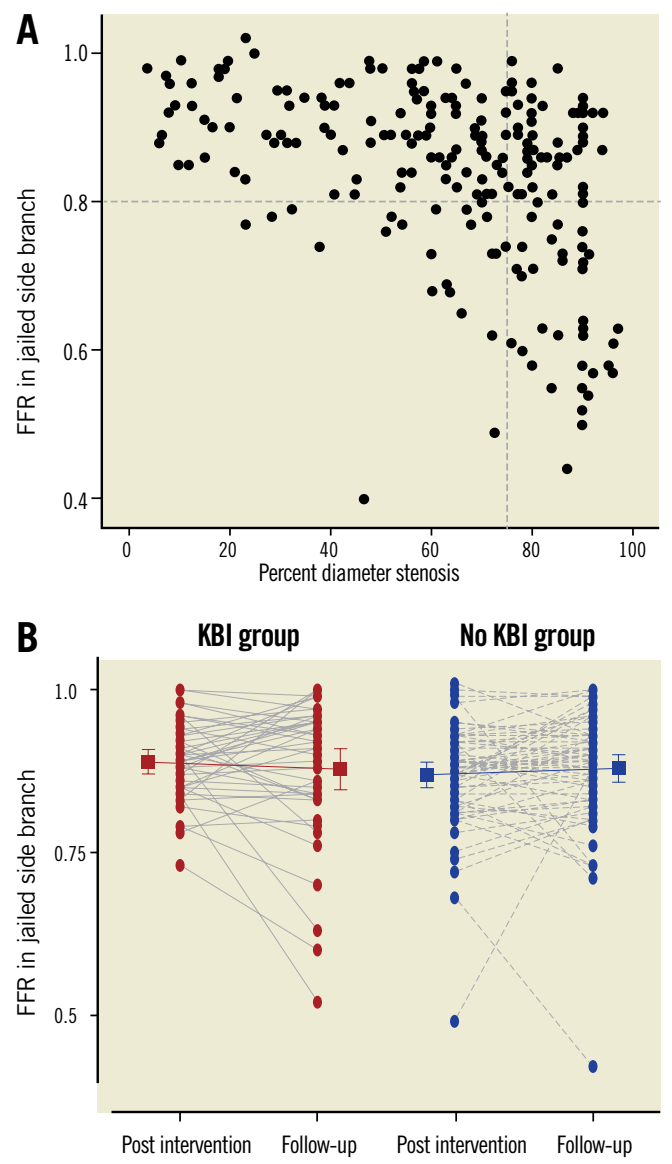

Figure 2. FFR and angiographic percent diameter stenosis in jailed side branches. A) The data of 242 jailed side branch lesions were pooled from the Seoul National University Hospital (SNUH) side branch FFR registry, the Nordic-Baltic Bifurcation III substudy and Bellenger et al ${ }^{14,16,18}$. Angiographic \% diameter stenosis showed a modest correlation with FFR $(r=-0.423, p<0.001)$. Using receiver-operating curve analysis, the AUC of \% diameter stenosis to predict FFR $<0.80$ was 0.729 (95\% CI: 0.656-0.801, $p<0.001$ ). $B)$ Among the 242 jailed side branch lesions, 113 lesions underwent serial FFR measurement at six to eight-month follow-up ${ }^{9,16}$. Side branch FFR was maintained regardless of final KBI or not $(0.89 \pm 0.06$ to $0.88 \pm 0.11$ in the final KBI group [ $p=0.406]$ and $0.87 \pm 0.08$ to $0.88 \pm 0.09$ in the no KBI group [p=0.332]).

FFR: fractional flow reserve; KBI: kissing balloon inflation 
Table 2. Summary of previous studies.

\begin{tabular}{|c|c|c|}
\hline Author and year & Study population & Main results \\
\hline \multicolumn{3}{|c|}{ Discrepancy between angiographic and functional severity in side branch lesions } \\
\hline Koo BK et al 2005 & $\begin{array}{l}94 \text { jailed SB } \\
\text { QCA vs. FFR }\end{array}$ & $\begin{array}{l}\text { 1. Negative correlation between } \% D S \text { and FFR }(r=-0.41, p<0.001) \text {. } \\
\text { 2. No lesion with }<75 \% \text { stenosis had FFR }<0.75 \text {. } \\
\text { 3. Among } 73 \text { lesions with } \geq 75 \% \text { stenosis, } 20 \text { lesions }(27 \%) \text { had FFR }<0.75 \text {. }\end{array}$ \\
\hline \begin{tabular}{|l|l} 
Bellenger et al \\
2007
\end{tabular} & $\begin{array}{l}14 \text { jailed SB } \\
\text { QCA vs. FFR } \\
\end{array}$ & $\begin{array}{l}\text { 1. No correlation between } \% D S \text { and FFR }(r=-0.54, p=0.053) \text {. } \\
\text { 2. Among } 9 / 14(64 \%) \text { lesions with } \% D S>50 \%, 3 \text { lesions }(21 \%) \text { were } \mathrm{FFR}<0.75 \text {. }\end{array}$ \\
\hline Koo BK et al 2010 & $\begin{array}{l}77 \text { bifurcation lesions } \\
\text { MB IVUS and SB FFR }\end{array}$ & $\begin{array}{l}\text { 1. Plaque volume index was decreased in the proximal MB after stenting (suggested "plaque shift"), but not } \\
\text { in distal MB (suggested "carina shift"). } \\
\text { 2. Pre-intervention \%DS and MLD of downstream main vessel stenosis were independent predictors for } \\
\text { functionally significant jailed SB. }\end{array}$ \\
\hline Koh JS et al 2012 & $\begin{array}{l}55 \text { SB ostial lesions } \\
\text { QCA, IVUS and FFR }\end{array}$ & $\begin{array}{l}\text { 1. In SB ostial lesions, there was no correlation between } \% \text { DS and FFR ( } r=-0.190, p=0.164) \text {. } \\
\text { 2. Negative remodelling was more frequent in } S B \text { ostial lesions than in MB ostial lesions }(72.7 \% \text { vs. } 52.6 \% \text {, } \\
p=0.046) \text {. } \\
\text { 3. AUC of } S B \% D S \text { for FFR } \leq 0.8 \text { was } 0.60 \text {. The PPV of } \% D S \text { for FFR } \leq 0.8 \text { was } 38 \% \text {, but NPV was } 82 \% \text {. } \\
\left.\text { 4. The PPV and NPV of IVUS MLA }\left(1.8 \mathrm{~mm}^{2}\right) \text { or percent plaque burden ( } 56 \%\right) \text { to predict FFR } \leq 0.80 \text { were only } \\
50 \% \text { and } 44 \% \text {. }\end{array}$ \\
\hline Ahn JM et al 2012 & $\begin{array}{l}230 \text { jailed SB } \\
\text { Dedicated bifurcation QCA vs. FFR }\end{array}$ & $\begin{array}{l}\text { 1. Negative correlation between } \% \text { DS and FFR }(r=-0.21, p=0.002) \text {. } \\
\text { 2. Among } 163 \text { lesions with } \leq 50 \% \text { stenosis, } 22 \text { lesions }(13.5 \%) \text { had } F F R \leq 0.80 \text {. Among } 67 \text { lesions with } \\
>50 \% \text { stenosis, } 19 \text { lesions }(28.4 \% \text { ) were functionally significant (FFR } \leq 0.80) \text {. } \\
\text { 3. Pre-interventional \%DS was an independent predictor for functionally significant jailed } S B \text {. }\end{array}$ \\
\hline $\begin{array}{l}\text { Nordic-Baltic } \\
\text { Bifurcation III } 2012\end{array}$ & $\begin{array}{l}75 \text { jailed SB } \\
\text { Dedicated bifurcation QCA vs. FFR }\end{array}$ & $\begin{array}{l}\text { 1. Negative correlation between } \% \mathrm{DS} \text { and side branch FFR after } \mathrm{PCl} \text { and at } 8 \text {-month follow-up ( } r=-0.37 \text {, } \\
p=0.001 ; r=-0.57, p<0.001 \text {, respectively). } \\
\text { 2. } 24 / 75 \text { patients }(32 \% \text { ) showed }>50 \% \text { stenosis, while FFR }<0.75 \text { was found in only } 6 \text { patients }(8 \%) \text {. }\end{array}$ \\
\hline Ha J et al 2014 & $\begin{array}{l}82 \text { jailed SB } \\
\text { MB 3D OCT vs. FFR }\end{array}$ & $\begin{array}{l}\text { 1. Best cut-off value of SB MLA was } 2.05 \mathrm{~mm}^{2} \text { (AUC } 0.81 \text { ). } \\
\text { 2. Diagnostic performance of MLA } 2.05 \mathrm{~mm}^{2} \text { versus FFR }<0.80 \text { : sensitivity } 71.0 \% \text {, specificity } 75.0 \% \text {, PPV } \\
54.5 \% \text {, NPV } 91.5 \% \text {. }\end{array}$ \\
\hline \multicolumn{3}{|c|}{ Serial FFR measurement in jailed side branch } \\
\hline Koo BK et al 2008 & $\begin{array}{l}100 \text { patients with provisional strategy } \\
\text { Repeated SB FFR at 6-month follow-up } \\
(n=65) .\end{array}$ & $\begin{array}{l}\text { 1. At } 6 \text {-month follow-up, there were no changes in FFR in lesions with }(0.86 \pm 0.06 \text { to } 0.84 \pm 0.01, p=0.4) \text { and } \\
\text { without } S B \text { balloon angioplasty }(0.87 \pm 0.06 \text { to } 0.89 \pm 0.07, p=0.1) \text {. } \\
\text { 2. Binary restenosis rate was } 48 \% \text {; however, functional restenosis (FFR }<0.75) \text { rate was } 8 \%(5 / 65) \text {. There } \\
\text { were no changes in SB FFR during the 8-month follow-up period ( } 0.92 \text { to } 0.91, p=0.80 \text { in } \mathrm{KBI} \text { group and } \\
0.87 \text { to } 0.87, p=0.91 \text { in no KBI group). }\end{array}$ \\
\hline $\begin{array}{l}\text { Nordic-Baltic } \\
\text { Bifurcation III } 2012\end{array}$ & $\begin{array}{l}75 \text { patients with provisional strategy } \\
\text { Repeated SB FFR at 8-month follow-up }(n=46)\end{array}$ & $\begin{array}{l}\text { There were no changes in SB FFR during the 8-month follow-up period ( } 0.92 \text { to } 0.91, p=0.80 \text { in final } \mathrm{KBI} \\
\text { group and } 0.87 \text { to } 0.87, p=0.91 \text { in no final } \mathrm{KBI} \text { group) }\end{array}$ \\
\hline \multicolumn{3}{|c|}{ FFR-guided PCI vs. Angio-guided PCI for jailed side branch } \\
\hline Koo BK et al 2008 & $\begin{array}{l}110 \text { patients with provisional strategy, SB } \\
\text { intervention when FFR }<0.75 \text {. Control group: } \\
110 \text { patients without FFR measurements. }\end{array}$ & $\begin{array}{l}\text { 1. The FFR-guided group showed significantly less frequent SB intervention ( } 30 \% \text { in FFR-guided vs. } 45 \% \text { in } \\
\text { angiography-guided group, } p=0.03 \text { ). } \\
\text { 2. There was no difference in } 9 \text {-month TVR ( } 4.6 \% \text { vs. } 3.7 \%, p=0.7 \text { ). }\end{array}$ \\
\hline DKCRUSH-VI 2014 & $\begin{array}{l}320 \text { patients with Medina } 1,1,1 \text { or } 0,1,1 \\
\text { bifurcation lesions. Randomly assigned to } \\
\text { FFR-guided (FFR }<0.80 \text { ) or angiography- } \\
\text { guided SB treatment. }\end{array}$ & $\begin{array}{l}\text { 1. Treatment of SB was less in FFR-guided group than in angiography-guided group ( } \mathrm{SB} \text { stenting: } 25.9 \% \text { vs. } \\
38.1 \%, \mathrm{p}=-0.01 \text { ). } \\
\text { 2. MACE (cardiac death, MI, TVR) rate at } 1 \text { year was comparable ( } 18.1 \% \text { vs. } 18.1 \%, p=1.00) \text {. Restenosis at } \\
\text { distal MB was more frequent in angiography-guided group than in FFR-guided group ( } 9.2 \% \text { vs. } 1.2 \% \text {, } \\
\mathrm{p}=0.01 \text { ). }\end{array}$ \\
\hline
\end{tabular}

FFR: fractional flow reserve; IVUS: intravascular ultrasound; KBI: kissing balloon inflation; MACE: major adverse cardiovascular events; MI: myocardial infarction; MLA: minimum lumen area; NPV: negative predictive value; OCT: optical coherence tomography; \%DS: percent diameter stenosis; PPV: positive predictive value; QCA: quantitative coronary angiography; SB: side branch; TIMI: Thrombolysis In Myocardial Infarction; TVR: target vessel revascularisation

ischaemia. The different clinical, electrocardiographic, and physiologic relevances between main and side branches were recently demonstrated by one-minute occlusion test ${ }^{22}$. In this study, occlusion of the diagonal branch resulted in less pain, less ST-segment elevation and fewer QT-segment disturbances than LAD occlusion $^{22}$. Therefore, to prove the benefit of revascularisation of side branch intervention over medical treatment, clinically significant side branches which supply large myocardial territory should be identified prior to FFR measurement. However, the best method to determine clinically significant side branches still remains unclear. In a BBC/Nordic Bifurcation Study population, a provisional strategy was better than a two-stenting strategy in all subgroups including large side branches $(>2.75 \mathrm{~mm}$ in diameter or equivalence between main and side branches) ${ }^{23}$. Recently, a scoring system incorporating a combination of three angiographic parameters (size, number, and location of side branches) was reported to discriminate the clinical relevance of side branches better than vessel size alone ${ }^{22}$. Further studies are needed to define clinically relevant side branches better in the catheterisation laboratory.

\section{INFLUENCE OF DOWNSTREAM OR UPSTREAM STENOSIS ON FFR}

The pressure gradient is dependent on the flow across a stenosis. As blood flow to the side branch is less than that to the main 
branch, side branch FFR is more easily influenced by the presence of additional upstream and downstream stenoses. Therefore, careful angiographic assessment and pressure pullback tracing under sustained hyperaemia are mandatory to understand the meaning of low FFR in a side branch adequately (Figure 3). By a more complicated interaction of a branching system, the presence of a critical stenosis at one branch can divert flow more to the other branch and influence FFR value (branch steal phenomenon) ${ }^{24}$.

\section{FFR for left main bifurcation}

In general, similar principles for using FFR for non-left main bifurcation lesions can be applied to left main bifurcation lesions with a few caveats. First, the left main bifurcation is exposed to the highest blood flow in the human coronary circulation system, and both branches are clinically relevant. Second, as most patients with left main bifurcation lesions have additional stenoses, the influence of downstream stenoses on measured FFR value should always be considered (Figure 4). For instance, when there is a significant downstream stenosis in the proximal LAD in a patient with an intermediate distal left main lesion, FFR measured in a non-diseased left circumflex artery underestimates the severity of a left main lesion due to reduced coronary flow caused by downstream stenosis in the

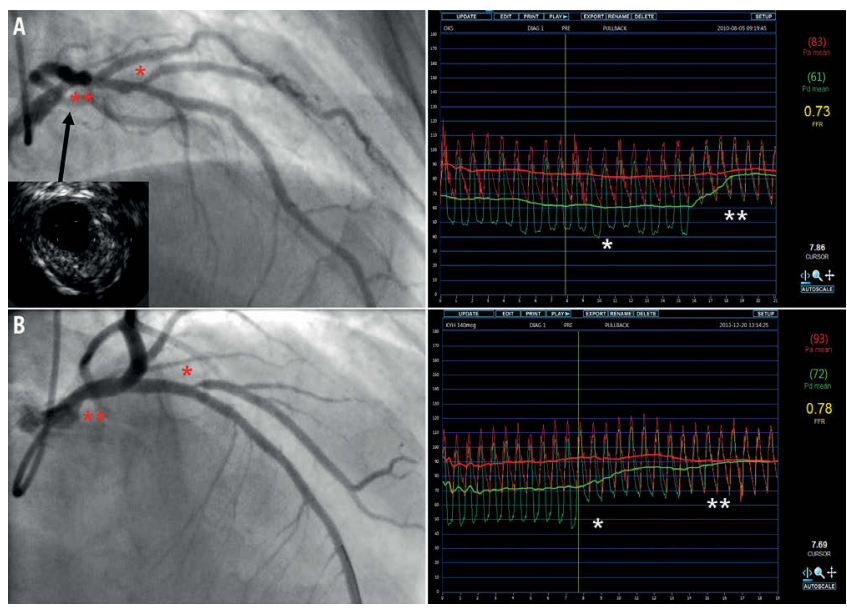

Figure 3. Influence of upstream stenosis on side branch FFR.

A) Angiography showed a Medina 0,0,1 lesion and FFR measured at a side branch was 0.73 . However, pressure pullback tracing from the diagonal branch to the left main ostium under sustained hyperaemia revealed the pressure step-up at the distal left main (**), but not at the ostium of the diagonal branch (*). This finding suggested that the primary lesion for low FFR was the distal left main lesion which was revealed by intravascular ultrasound. B) FFR measured at a side branch was 0.78 , and pressure step-up mainly occurred at the side branch ostium (*), not at the distal left main (**). These two cases show the importance of pressure pullback tracing to determine the relative contribution of proximal main branch and side branch lesions for side branch FFR. FFR: fractional flow reserve

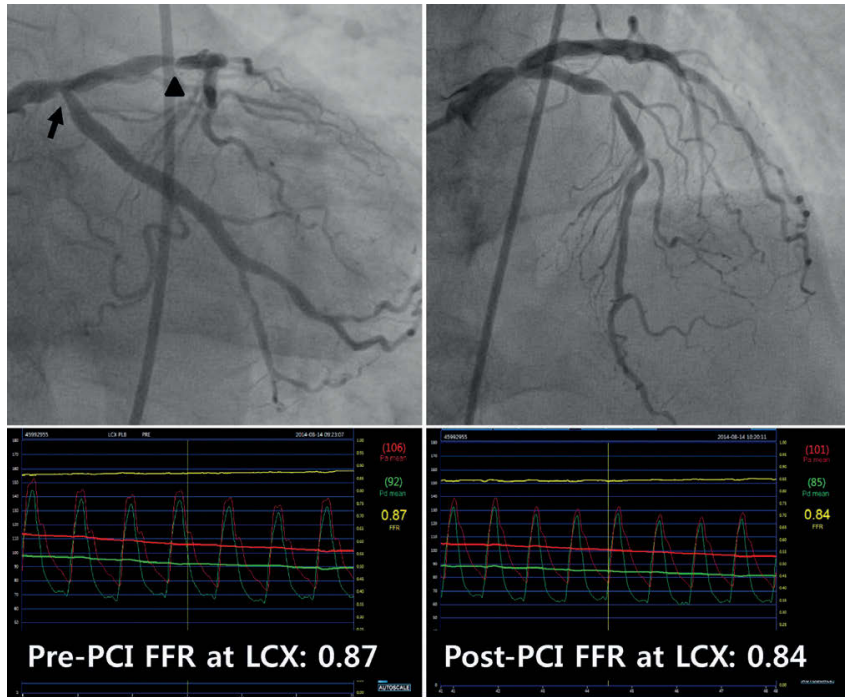

Figure 4. FFR for intermediate left main disease with a downstream stenosis. This patient had intermediate stenoses at the left main coronary artery and at the ostium of LCX and critical stenoses at $L A D$. Before the intervention of $L A D$ stenoses, FFR measured at distal LCX was 0.87. After stenting of LAD stenoses, FFR at distal $L C X$ decreased to 0.84. FFR: fractional flow reserve; $L A D$ : left anterior descending coronary artery; LCX: left circumflex artery; PCI: percutaneous coronary intervention

proximal LAD. However, clinically significant FFR change occurs only when the downstream stenosis is located in the proximal portion of the coronary artery and is very severe ${ }^{25,26}$.

\section{Summary}

FFR is a useful tool for the evaluation of coronary bifurcation lesions. FFR can guide treatment strategy, simplify the procedure and reduce unnecessary complex interventions. However, the operator should have an adequate understanding of coronary bifurcation physiology and the possible pitfalls of FFR. Finally, it should be remembered that the ischaemic burden is more important than the presence of ischaemia or measured FFR value, and the risks/benefits of complex intervention should be incorporated into the treatment decision after FFR measurement.

\section{Conflict of interest statement}

B-K. Koo has received an institutional research grant from St. Jude Medical. N. Curzen has received an unrestricted research grant and speaker/consultancy fees from St. Jude Medical and speaker fees and educational funds from Volcano. The other authors have no conflicts of interest to declare.

\section{References}

The references can be found in the online version of the paper. 


\section{Online data supplement}

\section{References}

1. Koo BK, De Bruyne B. FFR in bifurcation stenting: what have we learned? EuroIntervention. 2010;6 Suppl J:J94-8.

2. Pijls NH, De Bruyne B, Peels K, Van Der Voort PH, Bonnier HJ, Bartunek J, Koolen JJ, Koolen JJ. Measurement of fractional flow reserve to assess the functional severity of coronaryartery stenoses. N Engl J Med. 1996;334:1703-8.

3. De Bruyne B, Fearon WF, Pijls NH, Barbato E, Tonino P, Piroth Z, Jagic N, Mobius-Winckler S, Rioufol G, Witt N, Kala P, MacCarthy P, Engstrom T, Oldroyd K, Mavromatis K, Manoharan G, Verlee P, Frobert O, Curzen N, Johnson JB, Limacher A, Nuesch E, Jüni P; FAME 2 Trial Investigators. Fractional flow reserve-guided PCI for stable coronary artery disease. $N$ Engl J Med. 2014;371: 1208-17.

4. Pijls NH, Fearon WF, Tonino PA, Siebert U, Ikeno F, Bornschein B, van't Veer M, Klauss V, Manoharan G, Engstrom T, Oldroyd KG, Ver Lee PN, MacCarthy PA, De Bruyne B; FAME Study Investigators. Fractional flow reserve versus angiography for guiding percutaneous coronary intervention in patients with multivessel coronary artery disease: 2-year follow-up of the FAME (Fractional Flow Reserve Versus Angiography for Multivessel Evaluation) study. J Am Coll Cardiol. 2010;56:177-84.

5. Pijls NH, van Schaardenburgh P, Manoharan G, Boersma E, Bech JW, van't Veer M, Bar F, Hoorntje J, Koolen J, Wijns W, de Bruyne B. Percutaneous coronary intervention of functionally nonsignificant stenosis: 5-year follow-up of the DEFER Study. $\mathrm{J}$ Am Coll Cardiol. 2007;49:2105-11.

6. Ziaee A, Parham WA, Herrmann SC, Stewart RE, Lim MJ, Kern MJ. Lack of relation between imaging and physiology in ostial coronary artery narrowings. Am J Cardiol. 2004;93:1404-7, A9.

7. Koo BK, Waseda K, Kang HJ, Kim HS, Nam CW, Hur SH, Kim JS, Choi D, Jang Y, Hahn JY, Gwon HC, Yoon MH, Tahk SJ, Chung WY, Cho YS, Choi DJ, Hasegawa T, Kataoka T, Oh SJ, Honda Y, Fitzgerald PJ, Fearon WF. Anatomic and functional evaluation of bifurcation lesions undergoing percutaneous coronary intervention. Circ Cardiovasc Interv. 2010;3:113-9.

8. Koo BK, Kang HJ, Youn TJ, Chae IH, Choi DJ, Kim HS, Sohn DW, Oh BH, Lee MM, Park YB, Choi YS, Tahk SJ. Physiologic assessment of jailed side branch lesions using fractional flow reserve. J Am Coll Cardiol. 2005;46:633-7.

9. Koo BK, Park KW, Kang HJ, Cho YS, Chung WY, Youn TJ, Chae IH, Choi DJ, Tahk SJ, Oh BH, Park YB, Kim HS. Physiological evaluation of the provisional side-branch intervention strategy for bifurcation lesions using fractional flow reserve. Eur Heart J. 2008;29:726-32.

10. Stankovic G, Lefevre T, Chieffo A, Hildick-Smith D, Lassen JF, Pan M, Darremont O, Albiero R, Ferenc M, Finet G, Adriaenssens T, Koo BK, Burzotta F, Louvard Y; European Bifurcation Club. Consensus from the 7th European Bifurcation Club meeting. EuroIntervention. 2013;9:36-45.
11. Koh JS, Koo BK, Kim JH, Yang HM, Park KW, Kang HJ, Kim HS, Oh BH, Park YB. Relationship between fractional flow reserve and angiographic and intravascular ultrasound parameters in ostial lesions: major epicardial vessel versus side branch ostial lesions. JACC Cardiovasc Interv. 2012;5:409-15.

12. Park DW, Kim YH, Yun SC, Ahn JM, Lee JY, Kim WJ, Kang SJ, Lee SW, Lee CW, Park SW, Park SJ. Frequency, causes, predictors, and clinical significance of peri-procedural myocardial infarction following percutaneous coronary intervention. Eur Heart J. 2013;34:1662-9.

13. van Werkum JW, Heestermans AA, Zomer AC, Kelder JC, Suttorp MJ, Rensing BJ, Koolen JJ, Brueren BR, Dambrink JH, Hautvast RW, Verheugt FW, ten Berg JM. Predictors of coronary stent thrombosis: the Dutch Stent Thrombosis Registry. J Am Coll Cardiol. 2009;53:1399-409.

14. Bellenger NG, Swallow R, Wald DS, Court I, Calver AL, Dawkins KD, Curzen N. Haemodynamic significance of ostial side branch nipping following percutaneous intervention at bifurcations: a pressure wire pilot study. Heart. 2007;93:249-50.

15. Ahn JM, Lee JY, Kang SJ, Kim YH, Song HG, Oh JH, Park JS, Kim WJ, Lee SW, Lee CW, Kim JJ, Park SW, Park SJ. Functional assessment of jailed side branches in coronary bifurcation lesions using fractional flow reserve. JACC Cardiovasc Interv. 2012;5:155-61.

16. Kumsars I, Narbute I, Thuesen L, Niemela M, Steigen TK, Kervinen K, Sondore D, Holm NR, Lassen JF, Christiansen EH, Maeng M, Jegere S, Juhnevica D, Erglis A; Nordic-Baltic PCI study group. Side branch fractional flow reserve measurements after main vessel stenting: a Nordic-Baltic Bifurcation Study III substudy. EuroIntervention. 2012;7:1155-61.

17. Ha J, Kim JS, Mintz GS, Kim BK, Shin DH, Ko YG, Choi D, Jang Y, Hong MK. 3D OCT versus FFR for jailed side-branch ostial stenoses. JACC Cardiovasc Imaging. 2014;7:204-5.

18. Park SH, Koo BK. Clinical applications of fractional flow reserve in bifurcation lesions. J Geriatr Cardiol. 2012;9:278-84.

19. Chen SL, Ye F, Zhang JJ, Xu T, Tian NL, Liu ZZ, Lin S, Shan SJ, Ge Z, You W, Liu YQ, Qian XS, Li F, Yang S, Kwan TW, Stone GW. Randomized Comparison of FFR-guided and Angiography-guided Provisional Stenting of True Coronary Bifurcation Lesions: The DKCRUSH-VI Trial. JACC Cardiovasc Interv. 2015 Mar 17. [E-pub ahead of print].

20. Hachamovitch R, Hayes SW, Friedman JD, Cohen I, Berman DS. Comparison of the short-term survival benefit associated with revascularization compared with medical therapy in patients with no prior coronary artery disease undergoing stress myocardial perfusion single photon emission computed tomography. Circulation. 2003;107:2900-7.

21. Shaw LJ, Berman DS, Maron DJ, Mancini GB, Hayes SW, Hartigan PM, Weintraub WS, O'Rourke RA, Dada M, Spertus JA, 
Chaitman BR, Friedman J, Slomka P, Heller GV, Germano G, Gosselin G, Berger P, Kostuk WJ, Schwartz RG, Knudtson M, Veledar E, Bates ER, McCallister B, Teo KK, Boden WE; COURAGE Investigators. Optimal medical therapy with or without percutaneous coronary intervention to reduce ischemic burden: results from the Clinical Outcomes Utilizing Revascularization and Aggressive Drug Evaluation (COURAGE) trial nuclear substudy. Circulation. 2008;117:1283-91.

22. Koo BK, Lee SP, Lee JH, Park KW, Suh JW, Cho YS, Chung WY, Doh JH, Nam CW, Yu CW, Lee BK, Vassilev D, Gil R, Lim HS, Tahk SJ, Kim HS. Assessment of clinical, electrocardiographic, and physiological relevance of diagonal branch in left anterior descending coronary artery bifurcation lesions. JACC Cardiovasc Interv. 2012;5:1126-32.

23. Behan MW, Holm NR, Curzen NP, Erglis A, Stables RH, de Belder AJ, Niemela M, Cooter N, Chew DP, Steigen TK, Oldroyd KG, Jensen JS, Lassen JF, Thuesen L, Hildick-Smith D.
Simple or complex stenting for bifurcation coronary lesions: a patient-level pooled-analysis of the Nordic Bifurcation Study and the British Bifurcation Coronary Study. Circ Cardiovasc Interv. 2011;4:57-64.

24. Gould KL, Kirkeeide R, Johnson NP. Coronary branch steal: experimental validation and clinical implications of interacting stenosis in branching coronary arteries. Circ Cardiovasc Imaging. 2010;3:701-9.

25. Yong AS, Daniels D, De Bruyne B, Kim HS, Ikeno F, Lyons J, Pijls NH, Fearon WF. Fractional flow reserve assessment of left main stenosis in the presence of downstream coronary stenoses. Circ Cardiovasc Interv. 2013;6:161-5.

26. Daniels DV, van't Veer M, Pijls NH, van der Horst A, Yong AS, De Bruyne B, Fearon WF. The impact of downstream coronary stenoses on fractional flow reserve assessment of intermediate left main disease. JACC Cardiovasc Interv. 2012;5: 1021-5. 